\title{
Coherence Bandwidth and its Relationship with the RMS delay spread for PLC channels using Measurements up to $100 \mathrm{MHz}$
}

\author{
Mohamed Tlich', Gautier Avril ${ }^{2}$, Ahmed Zeddam ${ }^{2}$ \\ ${ }^{1}$ Teamlog, ${ }^{2}$ France Télécom division R\&D \\ 2, Av. Pierre Marzin - 22303 Lannion, France \\ Mohamed.tlich( $\omega$.wanadoo.fr
}

\begin{abstract}
Estimations of coherence bandwidth from wideband channel sounding measurements made in the $30 \mathrm{KHz}-100 \mathrm{MHz}$ band in several indoor environments are described. Results are intended for applications in high-capacity indoor powerline networks. The coherence bandwidth and the RMS delay spread parameters are estimated from measurements of the complex transfer function of the Powerline Communications (PLC) channel. The 90th percentile of the estimated coherence bandwidth at 0.9 correlation level is above $65.5 \mathrm{KHz}$ and $90 \%$ of estimated values of $B_{0.9}$ are below $691.5 \mathrm{KHz}$. $B_{0.9}$ was observed to have a minimum value of $32.5 \mathrm{KHz}$. The RMS delay spread describes the dispersion in the time domain due to multipath transmission. $80 \%$ of the channels exhibit an RMS delay spread between $0.06 \mu$ s and $0.78 \mu$ s. Its mean value was equal to $0.413 \mu$ s. The paper studies the variability of the coherence bandwidth and time-delay spread parameters with the channel class [9], and thus with the location of the receiver with respect to the transmitter. And finally relates the RMS delay spread to the coherence bandwidth, which in turn, affects the powerline channel capacity.
\end{abstract}

Keywords - Powerline Communications (PLC), Coherence bandwidth, RMS delay spread.

\section{- Introduction}

D owerline Communications (PLC) appointed for future wideband wireline services in the $2-30 \mathrm{MHz}$ frequency band envisage data transmission rates up to $200 \mathrm{Mbits} / \mathrm{s}$ [1]. Generally, Effective data rates do not exceed $70 \mathrm{Mbits} / \mathrm{s}$ [2]. In order to increase much more the data rates, the PLC equipment suppliers are studying the possibility of extending the PLC frequency band up to $100 \mathrm{MHz}$. The successful implementation of this solution requires a detailed knowledge of signal propagation modes inside this enlarged band.

Please use the following format when citing this chapter.

Tlich, M., Avril, G., 7eddam, A., 2007, in IFIP International Federation for Information Processing. Volume 256, Home Networking, Al Agha, K., Carcelle. X., Pujolle, G., (Boston: Springer), pp. 129-142. 
Extensive characterizations of powerline channels have been reported in $[5,6$, 7 , and 8]. However, these studies are mainly focused on frequencies up to 30 $\mathrm{MHz}$.

The coherence bandwidth is a key parameter whose value relative to the bandwidth of the transmitted signal, subsequently determines the need for employing channel protection techniques, e.g. equalisation or coding to overcome the dispersive effects of multipath $[3,4]$. The impulse response of transmission channels can be characterised by various parameters. The average delay is derived from the first moment of the delay power spectrum and is a measure of the mean delay of signals. The RMS delay spread is derived from the second moment of the delay power spectrum and describes the dispersion in the time domain due to multipath transmission.

For PLC channels, and for the 1-30 MHz frequency band, thorough studies were undertaken in $[5,6]$. It was observed that $99 \%$ of the studied channels have an RMS delay spread below $0.5 \mu \mathrm{s}$. In [5], $\mathrm{B}_{0.9}$ was observed to have an average value of $1 \mathrm{MHz}$.

Also, in [7], it was indicated that for signals in the $0.5-15 \mathrm{MHz}$ frequency band, the maximum excess delay was below $3 \mu \mathrm{s}$, and the minimum estimated value of $\mathrm{B}_{0.9}$ was $25 \mathrm{KHz}$.

In [8] and for the frequency range up to $30 \mathrm{MHz}$, it has been found that, for 95 $\%$ of the channels the mean-delay spread is between 160ns and $3.2 \mu \mathrm{s}$. And $95 \%$ of the channels exhibit an RMS delay spread between 240ns and $2.5 \mu \mathrm{s}$.

In this paper, coherence bandwidth and delay spread parameters studies are extended until the $100 \mathrm{MHz}$ frequency band. For this purpose wideband propagation measurements were undertaken in the $30 \mathrm{KHz}-100 \mathrm{MHz}$ band in various indoor channel environments (country and urban, new and old, apartments and houses) as demonstrated Table 1 .

The measurements taken using a swept frequency channel sounder yielded sufficient statistical data from which frequency correlation functions were derived. These results were used to obtain the coherence bandwidth of the PLC channels investigated and their impulse responses, obtained by applying the inverse Fourier transform to the estimated frequency response [4].

The PLC transfer functions study presented hereby relates to seven measurement sites and a total of 144 transfer functions. For each site, the transfer function is measured between a principal outlet (most probable to receive a PLC module) and the whole other outlets (except improbable outlets such as refrigerator outlets...). The distribution of the transfer functions by site and the characteristics of each site are given in the table 1.

TABLE 1

DISTRIBUTION OF TRANSFER FUNCTIONS BY SITE

\begin{tabular}{|c|c|c|}
\hline $\begin{array}{r}\text { Site } \\
\text { number }\end{array}$ & Site information & $\begin{array}{c}\text { Number of } \\
\text { transfer functions }\end{array}$ \\
\hline 1 & House - Urban & 19 \\
\hline 2 & New house - Urban & 13 \\
\hline
\end{tabular}


Coherence Bandwidth and its Relationship with the RMS delay spread for PLC channels using Measurements up to $100 \mathrm{MHz}$

\begin{tabular}{|c|c|c|}
\hline 3 & $\begin{array}{c}\text { Recently restored apartment - Ur- } \\
\text { ban }\end{array}$ & 12 \\
\hline 4 & Recent house - Urban & 28 \\
\hline 5 & Recent house - Urban & 34 \\
\hline 6 & Recent house - country & 22 \\
\hline 7 & Old House - country & 16 \\
\hline
\end{tabular}

Because calculating distances separating transmitters from receivers was impossible, the PLC channels were classified into 9 classes per ascending order of their capacities (according to the Shannon's capacity formula and for a same reference noise and PSD emission mask). In [9] and as shows Fig.1, we have demonstrated that the channels of each class had a transfer functions with a same average magnitude.

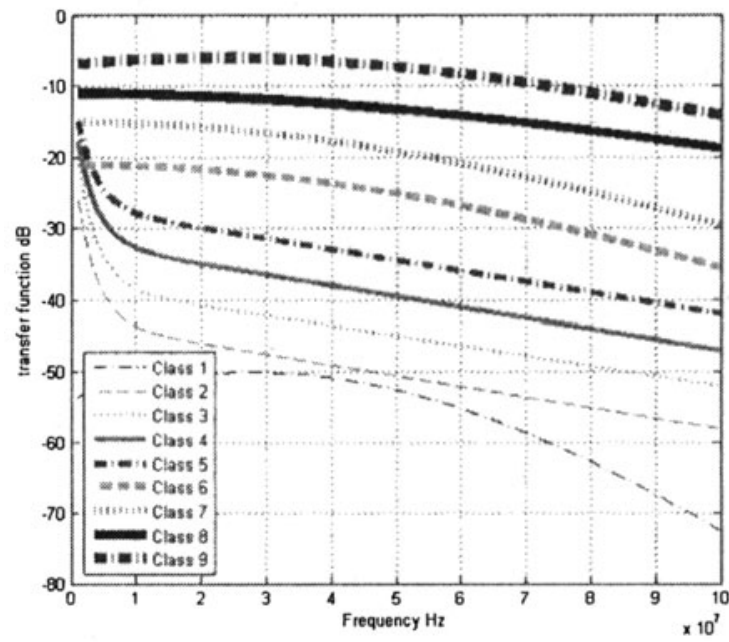

Fig. 1. Average transfer function magnitude by class.

Thus, a class 9 channel will, for example, be supposed to have a shorter transmitter-receiver distance than a class 2-8 channel, and so on.

\section{- Channel Sounder Hardware}

This section outlines the swept frequency channel sounder design, its calibration and the devices used in the measurements. Transfer function measurements were carried out in the frequency domain, by means of a vectorial network analyser, as show the block diagram of the Fig. 2.

The coupler box plugging into the AC wall outlet behaves like a high-pass filter, with the $3 \mathrm{~dB}$ cutoff at $30 \mathrm{KHz}$. The probing signal passes through the coupler 
and the AC power line network and exits through a similar coupler plugged in a different outlet. A direct coupler to coupler connection is used to calibrate the test setup.

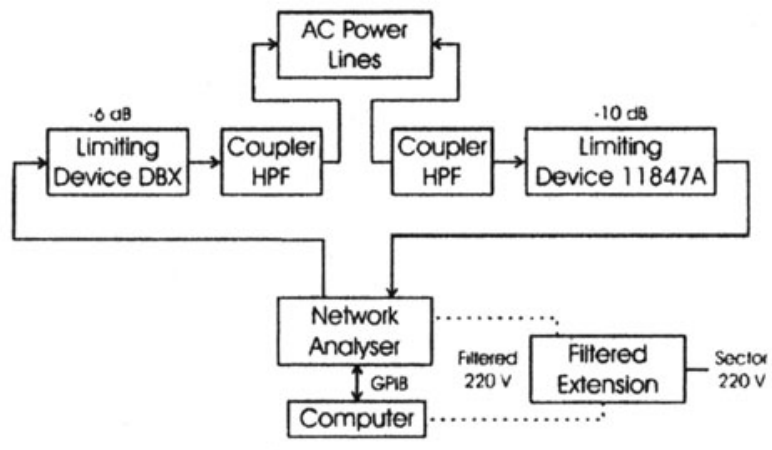

Fig. 2. Power line channel measurement system.

Two over-voltage limiting devices with a $-10 \mathrm{~dB}$ and $-6 \mathrm{~dB}$ losses, respectively, are used in front of the entry port of the vectorial network analyser 8753ES and its exit port, which can serve as an entry port, to protect it from over-voltages produced by the impulse noises of the AC power line.

A computer is connected to the network analyzer through a GPIB bus. This allows it to record data and control the network analyser by the INTUILINK software.

The network analyzer and the computer are isolated from the Powerline network using a filtered extension. This extension is systematically connected to an outlet nonlikely to be connected to a PLC modem, such as washing machine outlet. These precautions are taken in order to minimize the influence of the measurement devices on the measured transfer functions.

\section{- Wideband Propagation Parameters}

Characterisation of wideband channel performance subject to multipath can be usefully described using the coherence bandwidth and delay spread parameters.

\section{Coherence Bandwidth}

The frequency-selective behaviour of the channel can be described in terms of the auto-correlation function for a wide sense stationary uncorrelated scattering (WSSUS) channel. Equation (1) gives $R(\Delta f)$, the frequency correlation function (FCF):

$$
R(\Delta f)=\int_{-\infty}^{+\infty} H(f) H^{*}(f+\Delta f) d f
$$


Where $H(f)$ is the complex transfer function of the channel, $\Delta f$ is the frequency shift and ${ }^{*}$ denotes the complex conjugate. $R(\Delta f)$ is a measure of the magnitude of correlation between the channel response at two spaced frequencies. The coherence bandwidth is a statistical measure of the range of frequencies over which the FCF can be considered 'flat' (i.e. a channel passes all spectral components with approximately equal gain and linear phase).

In other words, coherence bandwidth is the range of frequencies over which two frequency components have a strong potential for amplitude correlation. It is a frequency-domain parameter that is useful for assessing the performances of various modulation techniques [10]. No single definitive value of correlation has emerged for the specification of coherence bandwidth. Hence, coherence bandwidths for generally accepted values of correlations coefficient equal to $0.5,0.7$ and 0.9 were evaluated from each $\mathrm{FCF}$, and these are referred to as $B_{0.5}, B_{0.7}$ and $B_{09}$, respectively.

\section{RMS Delay Spread}

Random and complicated PLC propagation channels can be characterized using the impulse response approach. Here, the channel is a linear filter with impulse response $h(t)$. The power-delay profile provides an indication of the dispersion or distribution of transmitted power over various paths in a multipath model for propagation. The power-delay profile of the channel is calculated by taking the spatial average of $|h(t)|^{2}$. It can be thought of as a density function, of the form:

$$
P(\tau)=\frac{|h(t)|^{2}}{\int_{-\infty}^{+\infty}|h(t)|^{2} d t}
$$

The RMS delay spread is the square root of the second central moment of a power-delay profile. It is the standard deviation about the mean excess delay, and is expressed as:

$$
\tau_{R M S}=\left[\int\left(\tau-\tau_{e}-\tau_{A}\right)^{2} P(\tau) d \tau\right]^{1 / 2}
$$

Where $\tau_{A}$ is the first-arrival delay, a time delay corresponding to the arrival of the first transmitted signal at the receiver; and $\tau_{e}$ is the mean excess delay, the first moment of the power-delay profile with respect to the first arrival delay:

$$
\tau_{e}=\int\left(\tau-\tau_{A}\right) P(\tau) d \tau
$$

The RMS delay spread is a good measure of the multipath spread. It gives an indication of the nature of the inter-symbol interference (ISI). Strong echoes (relative to the shortest path) with long delays contribute significantly to $\tau_{R M S}$.

A typical plot of the time delay parameters is shown in Fig. 3. 


\section{- $\quad$ Analysis of Results}

In this section, an analysis of the measured results, estimation of coherence bandwidth, its variability and interrelationship with RMS delay spread are outlined.

\section{Coherence Bandwidth Results}

Fig. 4 shows the frequency correlation functions obtained for three transmitter receiver scenarios; a class 9 channel (curve (i)), which can be assumed to have the least multipath contributions. Curves (ii) and (iii) correspond to the FCFs obtained from a class 6 and class 3 channels, respectively.

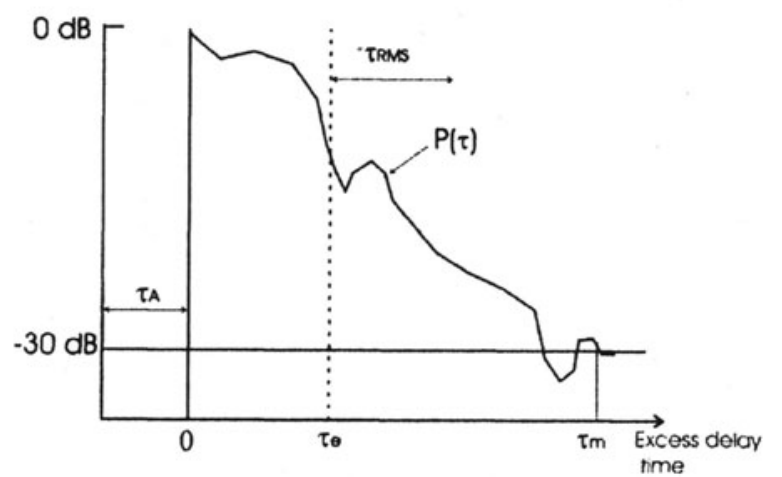

Fig. 3. An illustration of a typical power-delay profile and the definition of the delay parameters

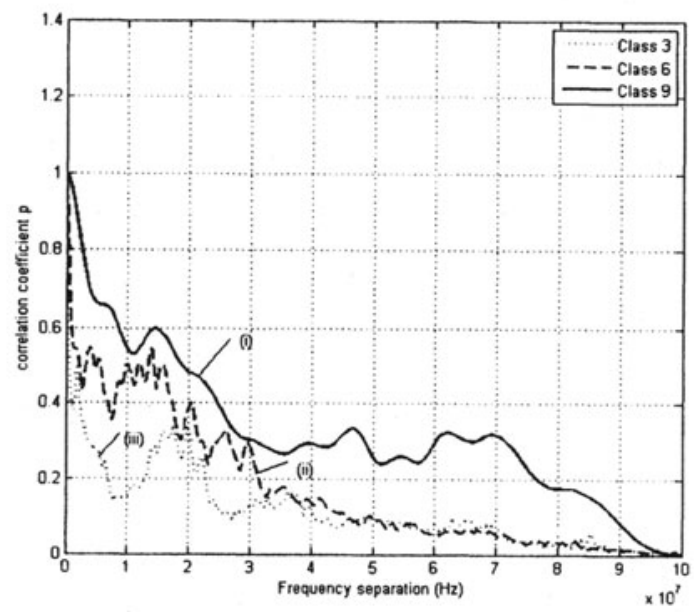

Fig. 4. Frequency correlation functions of the measured channels

(i) class 9; (ii) class 6; (iii) class 3 
The degradation of the frequency correlation functions corresponding to class 6 and class 3 channels with respect to the class 9 channel can be seen in Fig. 4 . Rapid decrease of the frequency correlation function with respect to the frequency separation and also as the class number decreases can be observed. The decrease in frequency correlation function is not monotonic, and this is due to the presence of multipath echoes in the PLC channel.

Coherence bandwidth values for $0.5,0.7$ and 0.9 correlation levels for the curves of Fig. 4 are given in Table 2, and statistics of the coherence bandwidth function for $0.5,0.7$ and 0.9 correlation levels for all channel measurements are shown in Table 3 . In general, the smallest frequency separation value is normally chosen to estimate the coherence bandwidth.

For the 0.9 coherence level, the coherence bandwidth was observed to have a mean of $291.97 \mathrm{KHz}$, minimum coherence bandwidth of $32.5 \mathrm{KHz}$, and 334.36 $\mathrm{KHz}$ standard deviation (Std). For $90 \%$ of the time, the value of $B_{0.9}$ obtained was below $691.5 \mathrm{KHz}$ and above $65.5 \mathrm{KHz}$. For the 0.7 coherence level, a mean coherence bandwidth of $833.9 \mathrm{KHz}$ was obtained. Here, the minimum value emerged as $98.5 \mathrm{KHz}$ and the standard deviation as $1.06 \mathrm{MHz}$. In the 0.5 coherence level, $80 \%$ of the channel measurements have a $B_{0.5}$ values below 13.376 $\mathrm{MHz}$ and above $423.5 \mathrm{KHz}$.

TABLE 2

COHERENCE BANDWIDTH VALUES FOR 0.5, 0.7 AND 0.9 CORRELATION LEVEL FOR THE CURVES OF FIG. 4

\begin{tabular}{|c|c|c|c|}
\hline \multirow{2}{*}{ Curve } & \multicolumn{3}{|c|}{ Coherence bandwidth $\mathrm{KHz}$} \\
\cline { 2 - 4 } & $\mathrm{B}_{05}$ & $\mathrm{~B}_{0.7}$ & $\mathrm{~B}_{0.9}$ \\
\hline (i) & 18819.5 & 3852.5 & 1586.5 \\
\hline (ii) & 2171.5 & 586.5 & 249.5 \\
\hline (iii) & 909.5 & 347.5 & 50.5 \\
\hline
\end{tabular}

TABLE 3

STATISTICS OF THE COIIERENCE BANDWIDTH FUNCTION FOR $0.5,0.7$, AND 0.9 CORRELATION LEVELS

\begin{tabular}{|c|c|c|c|c|c|c|}
\hline & $\begin{array}{l}M \\
\text { in }\end{array}$ & Max & $\begin{array}{l}\mathrm{Me} \\
\text { an }\end{array}$ & Std & $\begin{array}{r}9 \\
0 \% \\
\text { above } \\
\end{array}$ & $\begin{array}{r}90 \\
\% \text { be- } \\
\text { low }\end{array}$ \\
\hline $\begin{array}{r}\mathrm{B}_{0 \mathrm{~s}} \\
(\mathrm{KHz})\end{array}$ & $30^{2}$ & $\begin{array}{r}33 \\
850.5 \\
\end{array}$ & $\begin{array}{r}4 \\
539.3 \\
\end{array}$ & $\begin{array}{r}6 \\
544.7 \\
\end{array}$ & $\begin{array}{r}4 \\
23.5 \\
\end{array}$ & $376^{13}$ \\
\hline $\begin{array}{r}\mathrm{B}_{0.7} \\
(\mathrm{KHz})\end{array}$ & $\begin{array}{r}9 \\
8.5^{9} \\
\end{array}$ & $\begin{array}{r}8 \\
054.5 \\
\end{array}$ & $\begin{aligned} & 833 \\
& .9 \\
&\end{aligned}$ & $\begin{array}{r}1 \\
063.2 \\
\end{array}$ & $\begin{array}{r}1 \\
81.5 \\
\end{array}$ & $\begin{array}{r}1 \\
774.5 \\
\end{array}$ \\
\hline $\begin{array}{r}\mathrm{B}_{09} \\
(\mathrm{KHz})\end{array}$ & $2.5^{3}$ & $\begin{array}{r}1 \\
859.5 \\
\end{array}$ & $.97^{291}$ & $\begin{array}{r}334.3 \\
6 \\
\end{array}$ & $5.5^{6}$ & $\begin{array}{r}691 . \\
5\end{array}$ \\
\hline
\end{tabular}




\section{Coherence Bandwidth versus Channel Class}

The min, max, and mean values of coherence bandwidth function for 0.9 correlation level as a function of the channel class is given in Fig. 5. It can be observed that the coherence bandwidth is highly variable with the location of the receiver with respect to the transmitter.

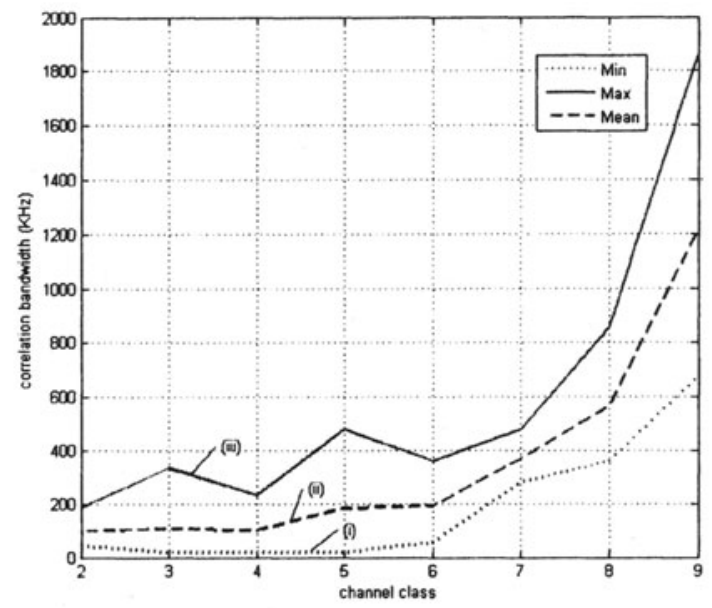

Fig. 5. Coherence bandwidth for 0.9 correlation level as a function of channel class. (i) Min; (ii) Mean; (iii) Max

To investigate the reasons for the fluctuations of the values of coherence bandwidth, magnitude curves of the complex frequency responses are shown. Fig. 6 represents the channel frequency response for the case where the coherence bandwidth was estimated at $1.859 \mathrm{MHz}$. This is the dominant peak value that appears in the curve (iii) of Fig. 5. Fig. 6 clearly shows that the channel frequency response presents few notches, large peaks, and is relatively flat over the $100 \mathrm{MHz}$ bandwidth. Not surprisingly therefore, the coherence bandwidth assumed a relatively high value. 
Coherence Bandwidth and its Relationship with the RMS delay spread for PLC

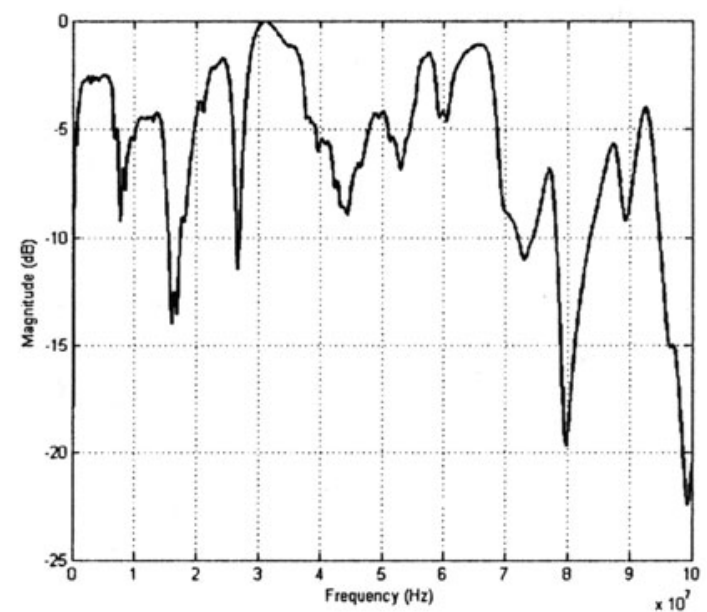

Fig. 6. Measured transfer function envelope of the maximum $B_{0}$ value

Next, the least value of the coherence bandwidth $(32.5 \mathrm{KHz})$ was investigated. Fig. 7 shows the magnitude response in this case which shows significant frequency selective fading of the channel, resulting in deep fades at several frequencies and narrow peaks. The presence of this significant frequency selective fading explains the relatively small value of coherence bandwidth observed. Both of these cases demonstrate that the PLC indoor channel is considerably affected by multipath, and that the coherence bandwidth value decreases with frequency selective fading.

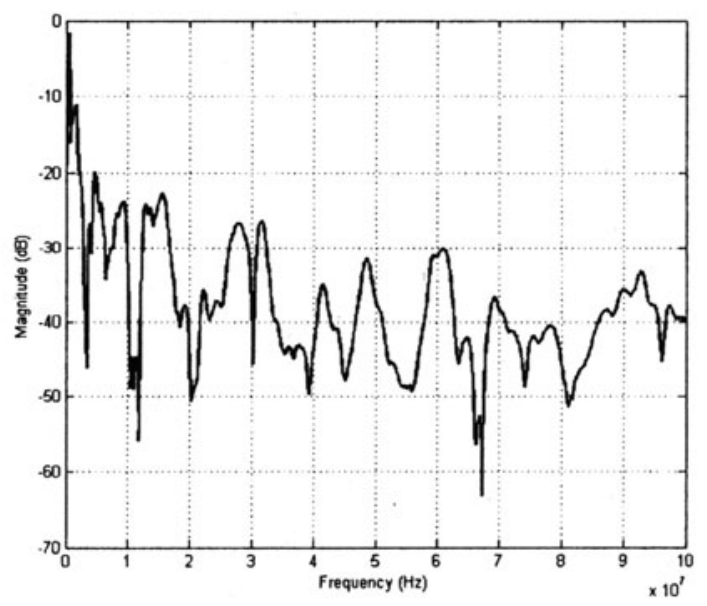


Fig. 7. Measured transfer function envelope of the minimum $B_{0.9}$ value

From an implementation point of view, the highly fluctuating coherence bandwidth means that the system designer can rely only on the lowest value of this parameter in such an environment. From Fig. 5 , this is $32.5 \mathrm{KHz}$.

The coherence bandwidth, determined from (1) is calculated from the complex frequency response of the channel, in which the phase changes instantaneously and significantly over any change on the state of an electrical device. The coherence bandwidth thus determined is more appropriately termed the instantaneous coherence bandwidth. To study the time dispersive nature of the PLC channel, it's more suitable to focus on the RMS delay spread parameter.

\section{Delay Spread Results}

By means of an inverse Fourier transform the impulsive response $h(t)$ can be derived from absolute value and phase of a measured transfer function. The amplitudes of the impulse responses of the channels of Fig. 6 and Fig. 7 are depicted in Fig. 8 and Fig. 9, respectively.

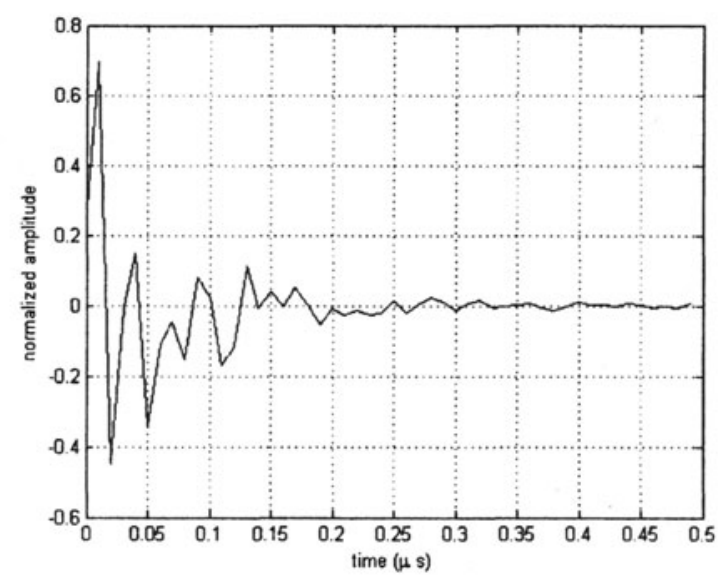

Fig. 8. Impulse response of the channel of Fig. 6. 
Coherence Bandwidth and its Relationship with the RMS delay spread for PLC

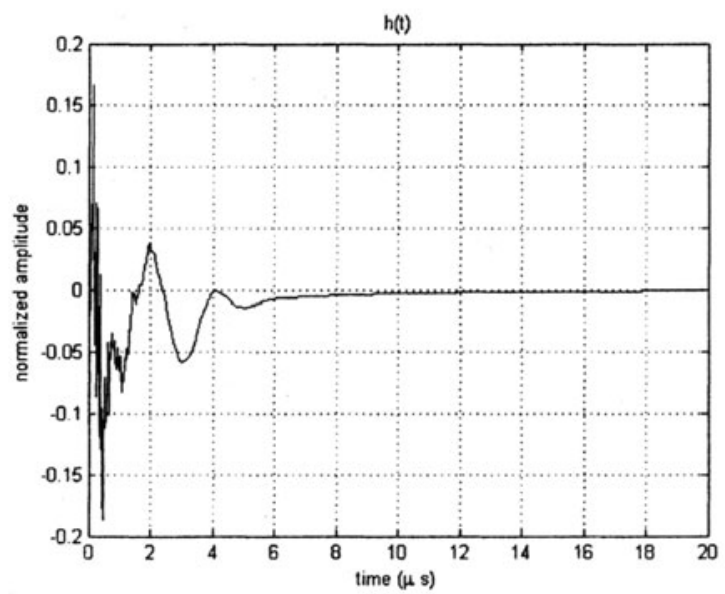

Fig. 9. Impulse response of the channel of Fig. 7.

The impulse responses of Fig. 8 and Fig. 9 show some peaks which confirm the multipath characteristics of PLC channels. The impulse response of Fig. 8 exhibits a maximum peak at a delay $\tau_{A}=0.01 \mu \mathrm{s}$ and an RMS delay spread $\tau_{R M S}=0.0368 \mu \mathrm{s}$. The same parameters of the impulse response of Fig. 9 are $\tau_{A}=0.32 \mu \mathrm{s}$ and $\tau_{R M S}=1.3674 \mu \mathrm{s}$. This is quite foreseeable as the impulse response of Fig. 8 is associated to a shorter PLC channel and much less affected by multipath.

Statistics of First arrival delay and RMS delay spread for all measured PLC channels are given in Table 4. The first-arrival delay $\left(\tau_{A}\right)$ was observed to have a mean of $0.175 \mu \mathrm{s}$, minimum of $0.01 \mu \mathrm{s}$, and $0.11 \mu \mathrm{s}$ standard deviation. $80 \%$ of the channels exhibit an RMS delay spread between $0.06 \mu$ s and $0.78 \mu \mathrm{s}$. The mean value of the RMS delay spread was $0.413 \mu \mathrm{s}$.

TABLE 4

STATISTICS OF TIME-DELAY SPREAD PARAMETERS

\begin{tabular}{|c|c|c|c|c|c|c|}
\hline & Min & $\begin{array}{l}\mathrm{Ma} \\
\mathrm{x}\end{array}$ & $\begin{array}{l}\mathrm{Me} \\
\text { an }\end{array}$ & Std & $\begin{array}{c}90 \\
\% \\
\text { above } \\
\end{array}$ & $\begin{array}{r}90 \\
\% \text { be- } \\
\text { low }\end{array}$ \\
\hline$\tau_{A}(\mu s)$ & 0.01 & $5 \begin{array}{l}0.5 \\
\end{array}$ & $751^{0.1}$ & $134^{0.1}$ & $05^{0 .}$ & 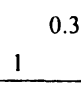 \\
\hline${ }^{\tau_{R M S}}(\mu \mathrm{s})$ & 0.027 & $67^{1.3}$ & $13^{0.4}$ & $94^{0.2}$ & $\begin{array}{r}0 . \\
066\end{array}$ & $84^{0.7}$ \\
\hline
\end{tabular}




\section{Delay spread versus Channel Class}

The mean values of first-arrival delay and RMS-delay spread as a function of the channel class are given in Fig. 10. It can be observed that these parameters are highly variable with the class number.

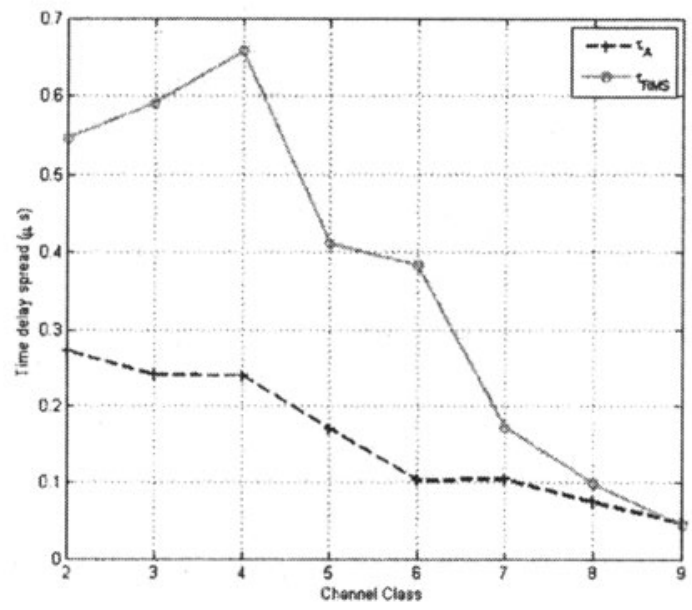

Fig. 10. Time-delay spread parameters as a function of the channel class

Generally speaking, the first arrival delay and RMS delay spread parameters decrease with the class number. In fact, the highly numbered classes are those whose channels are shorter and less affected by multipath. The transmitted signal arrives to its destination more quickly; furthermore, the number of echoes and their delay excess are less than those of low numbered classes.

An important fact is that the average value of the RMS delay spread of the class 4 channels is higher than that of classes 2 and 3 . Indeed, the relatively small number of measurements made that class 4 channels, although with higher average magnitude than those of the classes 2 and 3 channels, have many low valued coherence bandwidth channels (the $B_{0.9} 32.5 \mathrm{KHz}$ min value pertains to the class 4 ) and thus many RMS delay spread values relatively large.

\section{Coherence Bandwidth versus RMS Delay Spread}

Fig. 11 shows a scatter plot of the RMS delay spread against the coherence bandwidth of the PLC channel measures. The scatter plot shows a high concentration of points in the range $0.1 \mu \mathrm{s}-0.9 \mu \mathrm{s}$ at which the coherence bandwidth is almost under $500 \mathrm{KHz}$ and over $50 \mathrm{KHz}$. Higher values of coherence bandwidth are observed for RMS delay spread values less than $0.1 \mu \mathrm{s}$. In system design terms, higher coherence bandwidth translates to faster symbol transmission rates [10]. 
Coherence Bandwidth and its Relationship with the RMS delay spread for PLC

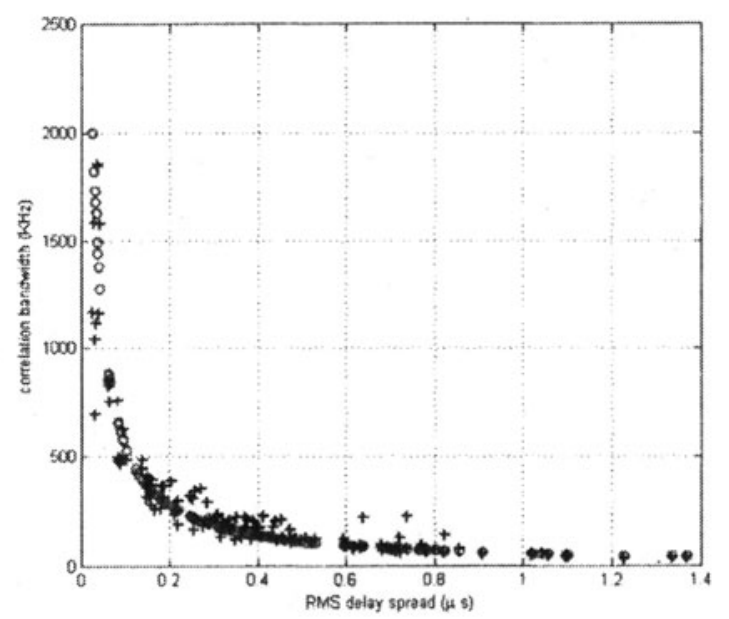

Fig. 11. Scatter plot of coherence bandwidth against RMS delay spread.

Fig. 11 depicts a clear relation between the values of $\mathrm{B}_{0.9}$ and $\tau_{R M S}$ estimated in the overall set of measured channels, and which can be approximated by:

$$
\tau_{R M S}(\mu s)=\frac{55}{B_{0.9}(\mathrm{KHz})}
$$

On Fig. 11, the relation (5) is represented by the red circles curve.

\section{- Conclusion}

Based on a multitude of measurements in different environments, the paper includes analysis of both coherence bandwidth and RMS delay spread parameters for in-house powerline channels in the frequency range up to $100 \mathrm{MHz}$.

Rapid decrease of the frequency correlation function with respect to frequency separation and also as the channel class increases was observed.

The 90th percentile of the estimated coherence bandwidth $B_{0.9}$ at 0.9 correlation level stayed above $65.5 \mathrm{KHz}$. Also, $90 \%$ of estimated values of $\mathrm{B}_{0.9}$ were below $691.5 \mathrm{KHz}$. $\mathrm{B}_{0.9}$ was observed to have a minimum value of $32.5 \mathrm{KHz}$.

The RMS delay spread results show that $80 \%$ of the channels exhibit values between $0.06 \mu$ s and $0.78 \mu \mathrm{s}$. Its mean value was equal to $0.413 \mu \mathrm{s}$.

Additionally, a relationship between the RMS delay spread and the coherence bandwidth was determined.

These results are intended for applications in high-capacity indoor powerline networks whose frequency band is up to $100 \mathrm{MHz}$. 


\section{REFERENCES}

[1] Homeplag Powerline Alliance, "HomePlug AV Specification, Version 1.0.05", October 2006.

[2] Sherman Gavette, Sharp Labs, "HomePlugAV - Detailed Architecture", homeplug executive seminar, November 2005.

[3] Bultitude R., Mahmoud S., and Sullivan W., "A comparison of indoor radio propagation characteristics at 910MHz and 1.75 GHz", IEEE J. Sel. Areus Commun., January 1989, 7, (I), pp. 2030.

[4] Bultitude R., Hahn R., and Davies R., "Propagation considerations for the design of indoor broadband communications system at EHF", IEEE Trans. Veh. Technol., February IYY8,47, (I), , pp. 20-30.

[5] V. Degardin, M. Lienard, A. Zeddam, F. Gauthier, and P. Degauque, "Classification and characterization of impulsive noise on indoor power lines used for data communications". IEEE Transactions on Consumer Electronics, Vol. 48, November 2002.

[6] T. Esmailian, F. R. Kschischang, and P. Glenn Gulak, "In-building power lines as high-speed communication channels: channel characterization and a test channel ensemble", Int. J. Comm. Sys. 2003.

[7] T. V. Prasad, S. Srikanth, C. N. Krishnan, and P. V. Ramakrishna, "Wideband Characterization of Low Voltage outdoor Powerline Communication Channels in India", International Symposium on Power-Line Communications and its Applications (ISPLC'2001), Sweden, April 2001.

[8] Holger Philipps, "Development of a Statistical Model for Powerline Communication Channels", Proceedings of ISPLC 2000, pp.153-162

[9] M. Tlich, A. Zeddam, F. Moulin, F. Gauthier, and G. Avril, " A Broadband Powerline Channel Generator", Proceedings of ISPLC 2007, pp. 505-510, 26-28 March 2007.

[10] Lutz H.-J. Lampe and Johannes B. Huber, "Bandwidth Efficient Power Line Communications Based on OFDM" 